\title{
P-0503 Effect of removal of glucotoxicity by SGLT2 inhibitor dapagliflozin on the gene expression in pancreatic beta cells
}

\author{
Shun-ichiro Asahara, Yoshiyuki Ohashi, Yoshiaki Kido \\ Kobe University Graduate School of Medicine, Department of Diabetes and Endocrinology \\ Kobe University Graduate School of Health Sciences, Department of Biophysics
}

$<$ Background and Aims>: To date, we have engaged in research on "the mechanism of regulation of pancreatic $\beta$-cell mass", which is one of the mechanisms of insulin secretion impairment, The sodium glucose cotransporter 2 (SGLT2) inhibitor is now used by patients with type 2 diabetes across many countries. Since the SGLT2 inhibitor has an effect of lowering blood glucose levels without the intervention of insulin, it is thought that the SGLT2 inhibitor does not exhaust pancreatic $\beta$ - cells. In addition, some studies report that pancreatic $\beta$-cell mass recovers by administration of SGLT2 inhibitor, because it plays a role in "releasing glucose toxicity" by lowering blood glucose levels. However, the effect of the timing of its initial administration of SGLT2 inhibitor on the phenotype has not been reported.Therefore, in this study, we examined how changing the timing and duration of administration of SGLT2 inhibitor influences metabolism data and pancreatic $\beta$-cell mass in type 2 diabetes mouse models.

<Methods >: Type 2 diabetic $\mathrm{db} / \mathrm{db}$ mice were classified into the following four groups, and the SGLT2 inhibitor Dapagliflozin (Dapa) and saline were administered accordingly:

Group1: Saline was administered from 9 weeks to 20 weeks of age. Group2: $1 \mathrm{mg} / \mathrm{kg}$ of Dapa was orally administered from 9 weeks to

14 weeks of age, and saline was administered from 15 weeks to 20 weeks of age.

Group3: Saline was administered from 9 weeks to 14 weeks of age and $1 \mathrm{mg} / \mathrm{kg}$ Dapa was orally administered from 15 weeks to 20 weeks of age.

Group4: $1 \mathrm{mg} / \mathrm{kg}$ Dapa was orally administered from 9 weeks of age to 20 weeks of age.

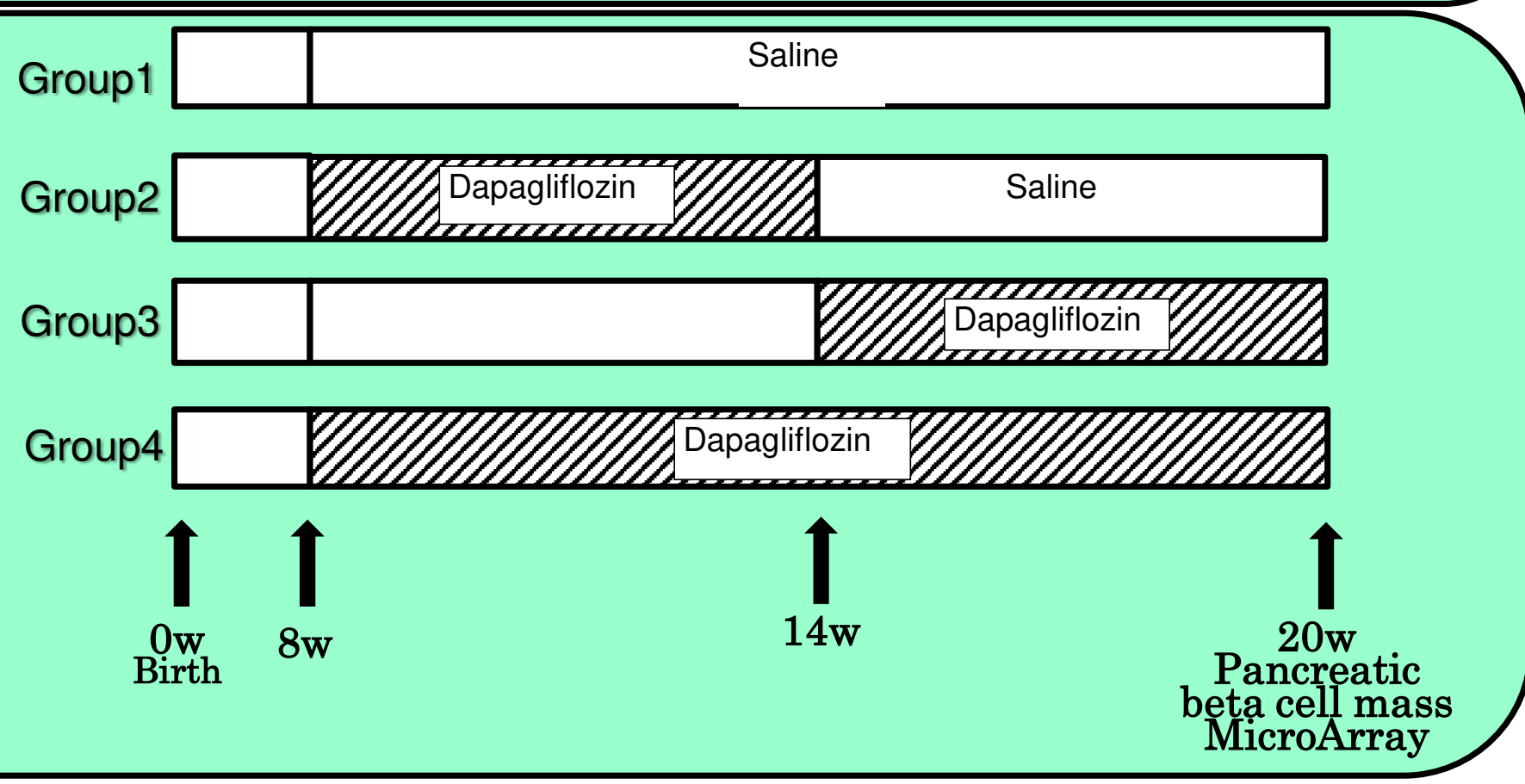

\section{Figure1. Body weight and Blood glucose}

$\mathrm{db} / \mathrm{db}$

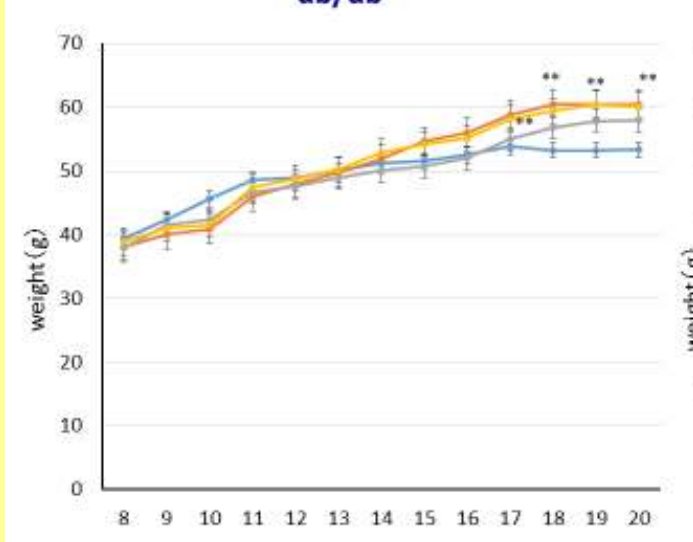

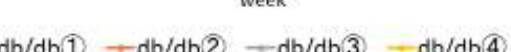

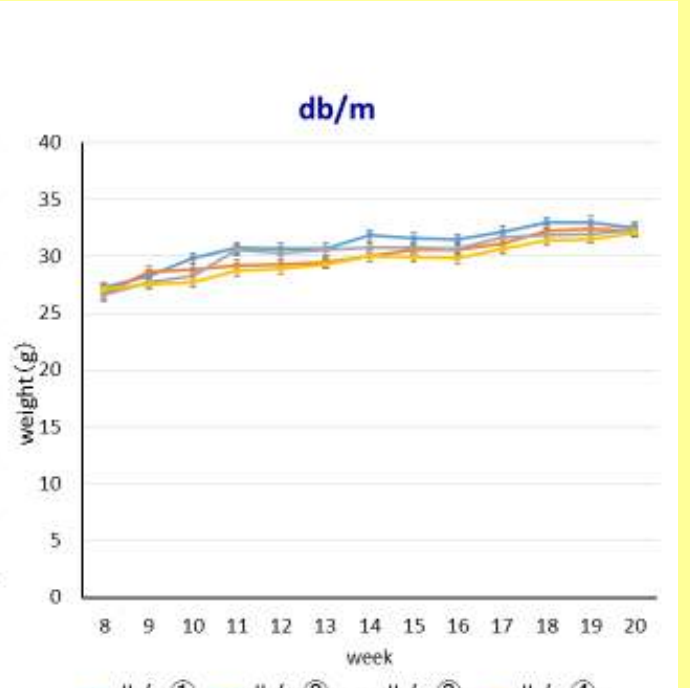

B

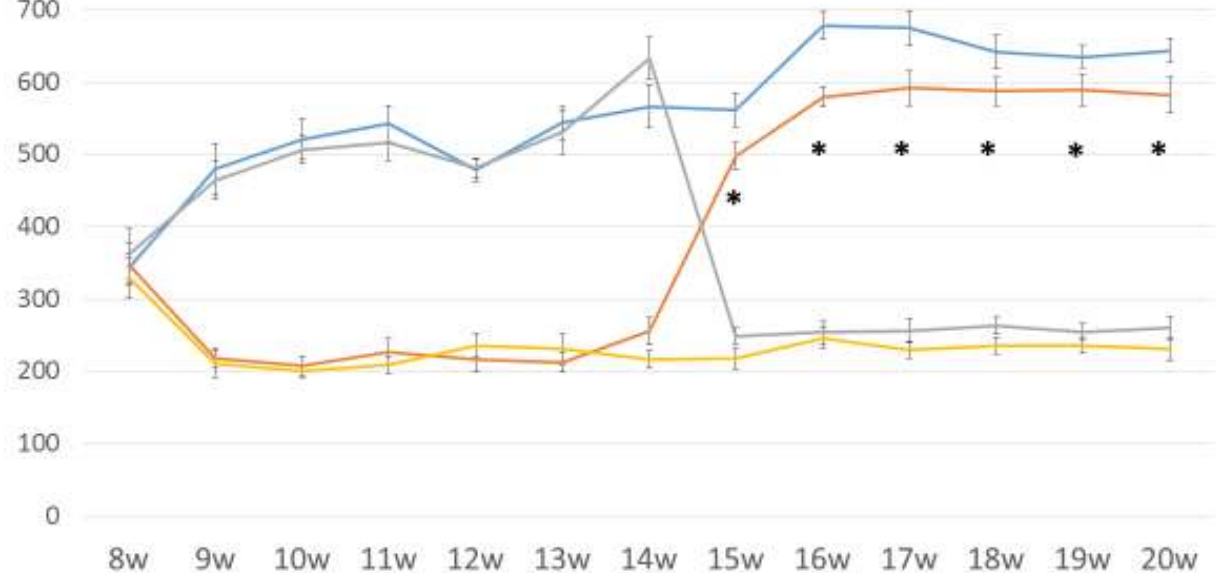

Body weights $(A)$ in Group1\&2 were higher than in Group 3\&4 from 17 to 20 weeks. Blood glucose levels (B) of Group2 abruptly increased upon stopping Dapa treatment, but it remained significantly lower than those of Group1.

\section{Figure2. Pancreatic beta cell mass}

The pancreatic $\beta$-cell mass was consistently maintained in Group2 and Group3, which received Dapa treatment for only 6 weeks (half the total period) compared to Group1. Particularly, in Group2, it was considered that the amount of pancreatic $\beta$-cell mass was considerably well maintained even after 6 weeks post completion of Dapa administration, associating with a significant difference in blood glucose level at 20 weeks of age.
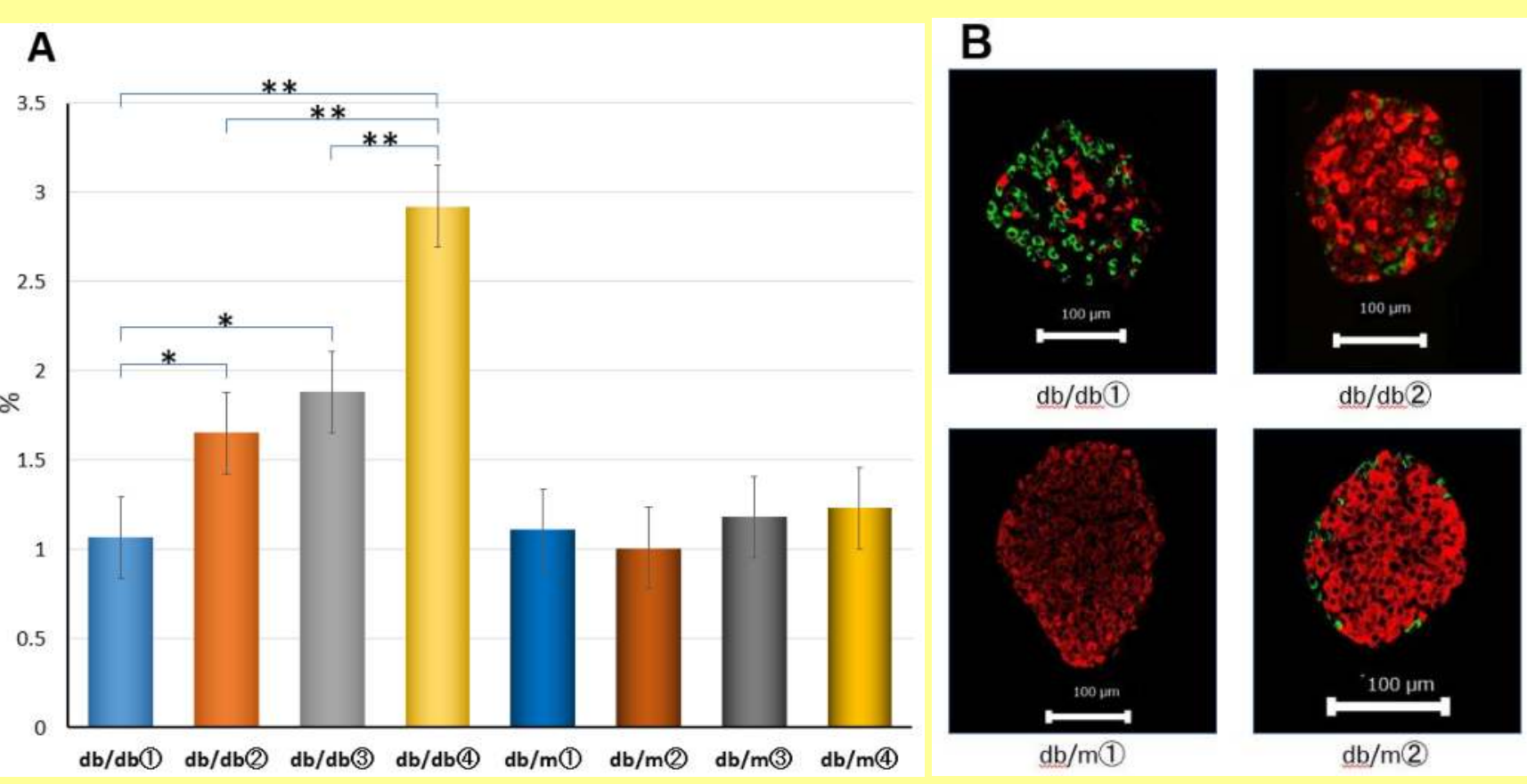

$\mathrm{db} / \mathrm{db}(2)$
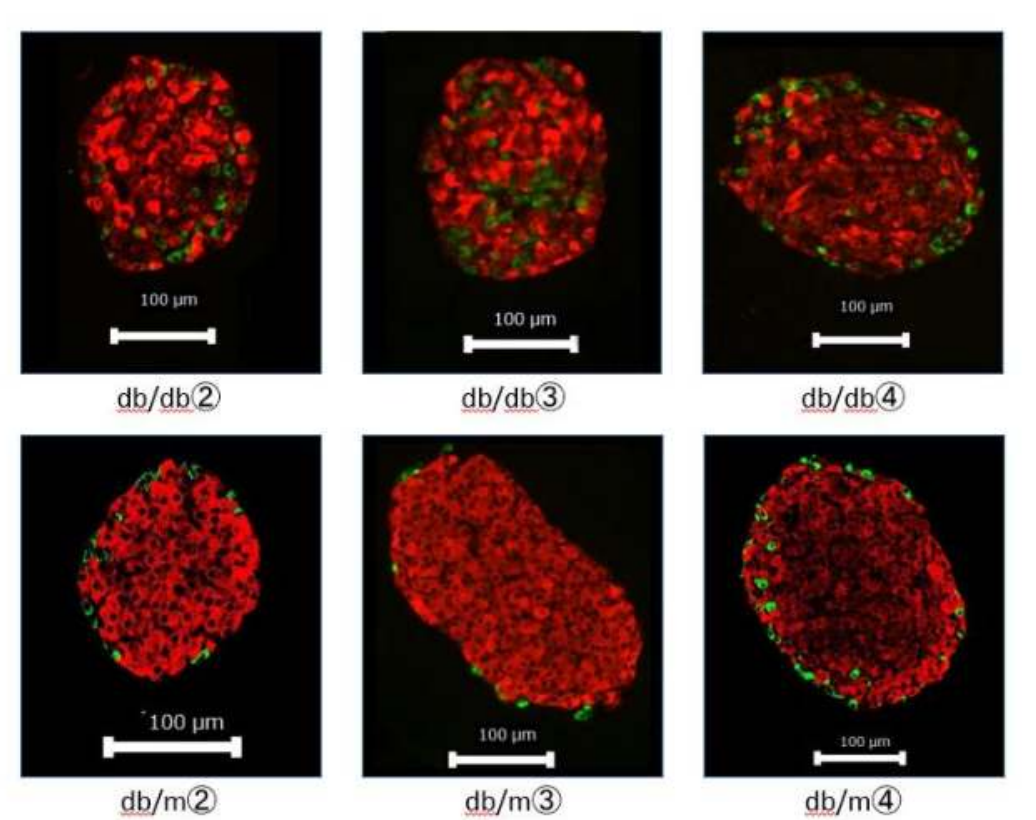

\section{Figure3. MicroArray}

Dapa administration from younger time may contribute to maintain beta cell mass. Thus, we focused on gene expression which were increased in Group2\&4, but not in Group3, by microarray analysis. Among the genes analyzed by microarray, the expressions of Agr2, Tff2 and Gkn3 were increased in Group2\&4, and no change between Group1 and Group3. Interestingly, Tff2 was previously reported to be involved in beta cell proliferation (Endocrinology, 2013).

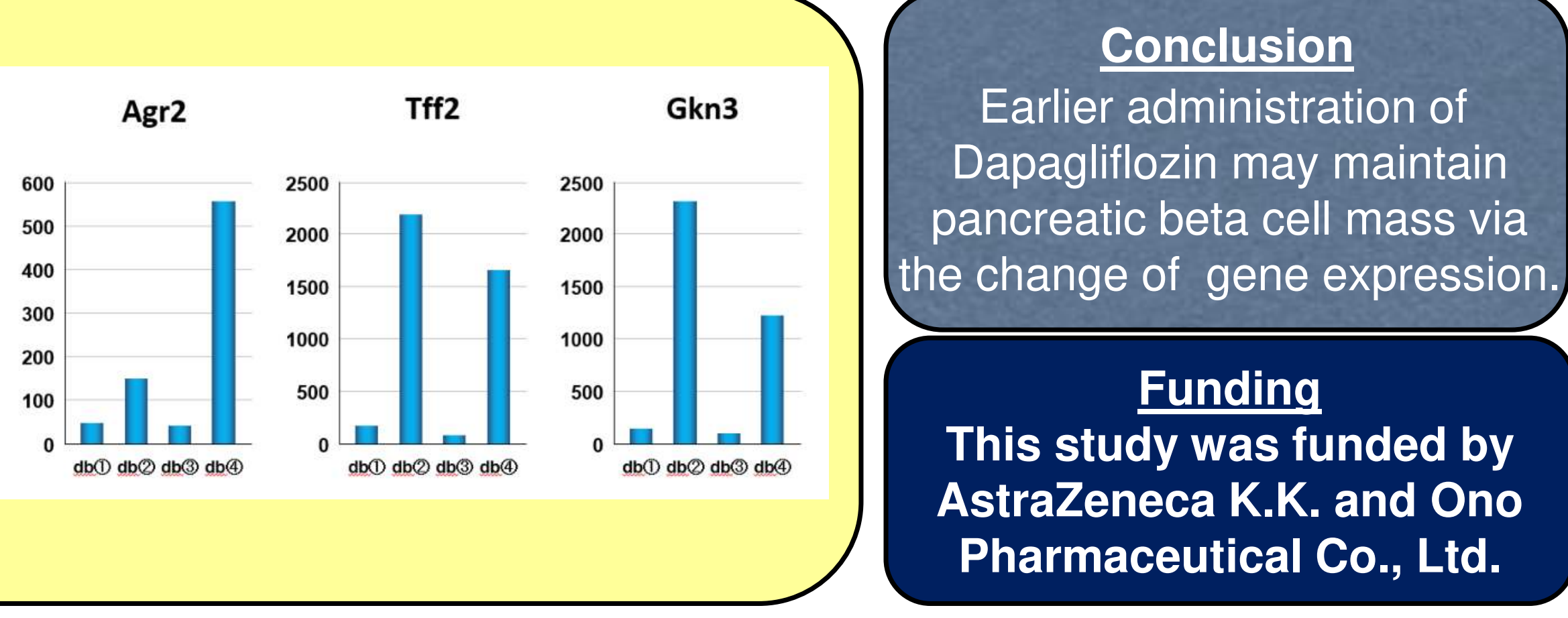

Earlier administration of

Dapagliflozin may maintain

pancreatic beta cell mass via the change of gene expression.

This study was funded by AstraZeneca K.K. and Ono Pharmaceutical Co., Ltd. 